\title{
Deploying culture as a defence against incompetence: The unconscious dynamics of public service work
}

\author{
Author: \\ Peliwe P. Mnguni ${ }^{1}$ \\ Affiliation: \\ ${ }^{1}$ Graduate School of Business \\ Leadership, University of \\ South Africa, South Africa \\ Correspondence to: \\ Peliwe P. Mnguni \\ Email: \\ pmnguni@sbleds.ac.za \\ Postal address: \\ PO Box 392, UNISA 0003, \\ South Africa \\ Dates: \\ Received: 31 May 2011 \\ Accepted: 05 Oct. 2011 \\ Published: 10 Jan. 2012 \\ How to cite this article: \\ Mnguni, P.P. (2012) \\ Deploying culture \\ as a defence against \\ incompetence: The \\ unconscious dynamics \\ of public service work. \\ SA Journal of Industrial \\ Psychology/SA Tydskrif vir \\ Bedryfsielkunde, 38(2), Art. \\ \#1000, 9 pages. http:// \\ dx.doi.org/10.4102/sajip. \\ v38i2.1000
}

Orientation: The intractability of public service delivery and a polarised societal landscape heighten anxiety and reinforce a propensity for public service organisations to be used for defensive purposes.

Research purpose: This article employs social defense theory to explore manifestations of anxiety and defense within South African public service organisations.

Motivation for the study: Dominant discourse on public service institutions over-relies on political, sociological and public administration theories and tends to ignore psychosocial explanations. Further, whilst the psychodynamics of social service work are generally understood, the unconscious dynamics of generic public service work remain under-theorised.

Research design, approach and method: This conceptual article draws on my personal observations as a reflective citizen and experiences as a consultant to government departments.

Main findings: Herein, an argument is advanced that the deployment of ill-qualified party loyalists to key positions in the public service is perverse: it serves as a collective defense against the impossible aspects of the task at hand. The appointees, in turn, deploy organisational processes to defend against feelings of incompetence and the inevitability of failure. This practice, coupled with acute resource constraints, sets up front line staff for scapegoating.

Practical/managerial implications: An appreciation of the multiple meanings of public service work and the defensive role played by public institutions stands to inform purposeful change towards sustainable public service organisational practice.

Contribution/value-add: The discussion seeks to contribute to attempts that employ systems psychodynamics to make sense of anxiety and defense within organisations in general and public service institutions in particular.

\section{Introduction}

The palpable mutual projective dynamics that characterise the public service delivery debate in South Africa are indicative of a society in the grip of paranoid anxiety. Both the racialisation and politicisation of public service delivery are manifestations of unrelenting splitting processes from the country's past. They enable different sections of society to project onto 'others' such negative qualities as racism, elitism, incompetence, corruption and greed, to mention but a few popular characterisations of contemporary public service organisations and officials in the country. It is my contention, herein, that task and relational tensions, as well as attendant defensive dynamics, are paralysing public service organisations. Caught in the midst of powerful forces, both conscious and unconscious, public service officials often cope by engaging in various forms of anti-task behaviour. This article seeks to explore how organisational processes, particularly organisational structure and culture, are being used for collective defence purposes. I suggest that when confronted with the impossible task of public service delivery, and as they find themselves operating in a highly contested societal and organisational landscape, some public officials simply give up on the public service task. They either leave public service altogether or remain in their jobs, but psychologically withdraw from the system and its primary task. The corrosive effect that this has on individual officials, public service delivery and wider society is examined.

\section{Study background}

To appreciate public service delivery issues in South Africa requires an understanding of the country's socio-political context, particularly its history. For more than four decades, the majority of the citizens were disenfranchised. There was, on the part of the apartheid regime, a deliberate 
agenda to under-develop designated 'Black' areas. The current dispensation, as such, inherited a lot of negative legacies, including either an aging infrastructure where some existed, or a nonexistent infrastructure in many parts of the country. Decades of an inferior education system had ensured, as it was indeed intended to, that managerial and technical skills were generally lacking amongst Black South Africans. Unlike the previous dispensation which provided adequate services for a very small fraction of the population, the new, largely inexperienced democratic government found itself with the 'self-assigned impossible task' (Roberts, 1994b, p. 110) of ensuring 'a better life for all' South Africans as provided for in the national constitution.

Seventeen years into the new democratic dispensation, however, this legacy narrative is losing its capacity to be a good-enough container for psycho-social fallouts from decades of alienation. For the current government to continue to evoke the apartheid monster when confronted with its shortcomings, and for various sections of society to continue to play the race card whenever things do not go their way, only serve to hold the country back in its maturational project. Such a stance helps keep the ghosts of the past alive, and in so doing, retards national healing and nation building. It accentuates the propensity for South African organisations, both public and private, to be used defensively, as repositories for societal projections. Whilst societies will always use their institutions in this way (Dartington, 2004; Hoggett, 2006; Jaques, 1955; Menzies-Lyth, 1988), efforts to understand and change public service organisations for the better must continue, if only to ensure that people's 'ways of coping do not grossly interfere, subvert, or even perverse' work efforts (Mawson, 1994, p. 77).

There is a need for alternative narratives to help disentangle the South African psyche from the grip of paranoid anxiety and from the spell of mutual projective processes that continue to colour people's experiences of both their personal and work lives. There is a need for new understandings to help shift the nation and its institutions towards a depressive state of functioning, one dominated by mature forms of relatedness. Only under such conditions of mutuality can sustaining and sustainable organisational practise become possible.

\section{Research purpose}

The need for alternative narratives presents an opportunity for the up-to-now marginalised perspectives to add their voice to the national discourse, including that on public service delivery. The psychodynamic perspectives employed in this article promise to yield the kind of complex insights that the issues at hand demand. Herein, social defense theory is used to explore some of the irrationality observed in South African public service organisations. I advance an argument that the deployment of ill-qualified party loyalists to key positions in the public service is perverse. It serves as a collective defence against the insurmountable aspects of public service work. The appointees, in turn, deploy organisational processes, specifically structure and culture, to defend against feelings of incompetence, and the inevitability of failure. This practice, coupled with acute resource constraints, sets up front-line staff for scapegoating whenever things go wrong - as they so often do.

This article builds on the growing body of work that extends psychodynamic insights to wider socio-cultural phenomena. It draws on and contributes to attempts that employ object relations thinking (Klein, 1959) to make sense of anxiety and defence within organisations in general (Bain, 1998; Cilliers \& May, 2010; Cummins, 2002; Gould, Ebers \& Clinchy, 1999; Jaques, 1955), social service institutions (BottSpillus, 1990; Gibson \& Swartz, 2000, 2001; Menzies-Lyth, 1988; Obholzer \& Roberts, 1994; Willshire, 1999) and public service organisations (Dartington, 2004; Dempsey, 2007; Hoggett, 2006; Mnguni, 2010, 2008). Whereas most of these studies concur that anxiety within public and social service organisations derives primarily from the intrinsic nature of their primary task, Hoggett (2006) problematises the very notion of a primary task as simplistic. He argues instead that anxiety in public service work emanates from the inherently contentious nature of the public service domain. Whilst I agree with Hoggett's assertion that the work of public service institutions is complex, I disagree with his suggestion that this then renders the primary task concept a less useful devise for making sense of unconscious dynamics within such institutions. I propose instead that anxiety in public service work results from both the intrinsic nature of the primary task(s) and the contentious nature of the wider socio-cultural landscape within which public service organisations find themselves.

\section{Social defense theory}

Social defense theory extends Klein's object relations thinking to the role and functioning of socio-cultural institutions. Specifically, the perspective suggests that members of society use social institutions for both creative and defensive purposes. At the individual level, people are said to join organisations to work not only on the explicit collective task, for example, health services in the case of hospitals, but also, albeit unconsciously, to deal with unresolved developmental issues from early infancy. As Jaques (1955, p. 482) put it, 'the character of institutions is determined and coloured not only by their explicit or consciously agreed and accepted functions, but also by their manifold unrecognized functions at the phantasy level'. For Jaques (1955, p. 496), therefore, 'one of the primary dynamic forces pulling individuals into institutionalized human association is that of defense against paranoid and depressive anxiety'. Similarly, at the collective level, families and whole societies are said to use social institutions as repositories for unwanted thoughts and feelings. Societies, according to Jaques (1955, p. 497), 'provide institutionalized roles whose occupants are sanctioned, or required, to take into themselves the projected objects or impulses of other members'. Such role occupants, depending on their psychological needs, either absorb or deflect the projections. In taking in societal projections, people become 
either good or bad objects, thereby relieving the rest of society of the kind of psychological pain that attends work that is inherently anxiety provoking and/or shame-inducing.

Accordingly, Jaques (1955) and Menzies-Lyth (1988) suggested that attempts to understand the functioning of social institutions must pay attention to both the explicit and unconscious levels. Drawing on these authors' pioneering work, later studies sought to demonstrate, amongst other things, that anxiety associated with social service professions derives in part from the capacity of the work to confront people with their own vulnerability and inevitable physical and psychological decline (Obholzer \& Roberts, 1994). Of particular note are studies that explored the unconscious dynamics of work with the elderly (Flinders, 2003; Roberts, 1994a), the physically disabled (Obhlozer, 1994), the terminally ill (Speck, 1994), the mentally ill (Bott-Spillus, 1990; Willshire, 1999) and sick or disabled children (Cohn, 1994; Gibson \& Swartz, 2001, 2000; Mawson, 1994). These and similar studies showed that ambivalent feelings about physical or psychological incapacitation manifest as empathy and compassion on the one hand, and as anger, contempt, horror, grief and shame on the other. Feelings of hostility and envy are also not uncommon as was the case with a female nurse whose work involved looking after young infants whilst herself undergoing fertility treatment (Cohn, 1994). Also common in social service work are feelings of helplessness and hopelessness mainly due to the fact that some clients' problems together with issues experienced by society are simply beyond the capacity of the workers to resolve (Dartington, 2004; Willshire, 1999).

Social service institutions are, of course, not unique in this regard. As Mawson (1994, p. 67) pointed out, 'there are mental pains to be borne in working at any task'. I therefore suggest that similar dynamics as those attending social service work should also characterise public service work in South Africa. Such is the nature of the socio-cultural landscape that most public service roles, including purportedly mundane administrative work, entail aspects of psycho-social support - at least for those who can still bother to care. There is, in my view, a lot that is painful and undesirable about working in the public service arena. That is especially the case for frontline staff as they are the ones at the coalface of what is, as suggested earlier, an impossible task. They are the ones that mobs of angry demonstrators turn against when patience with unfulfilled promises by politicians wanes. For such workers, to work in public service is to put their lives and the lives of loved ones at risk. Within a context of so much need, and indeed want, particularly within poor communities, working in public service also means being an object of innuendo and speculation. Whilst public officials are wayward at times, and whilst allegations of corruption and greed are often not without justification, it does seem that public officials also get attacked out of a desire to spoil things for them. Damage to their property, whilst often justified as an attack on ill-gotten gains, does also seem, sometimes, to be motivated by envy.
Collective defences manifest as members of social systems collude to use organisational processes to reinforce their individual defences. As Menzies-Lyth (1988) put it:

... the need for the members of the organization to use it in the struggle against anxiety leads to the development of socially structured defense mechanisms which appear as elements in the organization's structure, culture and mode of functioning. (Menzies-Lyth, 1988, p. 50)

The likelihood that there will be a good fit between individual and operating collective defences derives from the fact that particular professions and work settings tend to attract people with comparable emotional needs (Roberts, 1994). This, of course, does not mean there will always be a fit. Relational problems usually arise due to collective defences not being shared by all members of a social system (Menzies-Lyth, 1988; Mnguni, 2010, 2008). To the extent that organisational membership requires a good-enough fit between individual and collective defences, a significant gap between the two can culminate in the termination of a work relationship and/or organisational membership. If a member insists on using his or her misaligned individual defences, those whose psychological needs are better aligned with operating collective defences may reject members. The nonconforming behaviour might be hard to tolerate as it is likely to confront others with the 'unthought known' (Bollas, 1987) that their collective response might in fact be regressive.

Concurrently, those individuals whose defences do not map so well to dominant collective ones may come to experience group or organisational membership as destructive. The experience might raise issues of authenticity, and trying to fit in might be considered too high a price to pay for continued membership. If such individuals try to compromise and start to behave in a manner consistent with the rest of the membership, anxiety will most likely increase. Wastage and destructiveness eventuate as they end up putting up with alienating relationships, symbolically withdrawing from the system and its task, or leaving. In so doing, they withhold or withdraw from the system their alterity and a critical source of corrective feedback that their difference potentially represents. This is the kind of feedback that all social systems need to grow, and yet, it is paradoxically the very thing that human systems, particularly those plagued by anxiety, are likely to find threatening (Smith \& Berg, 1987a, 1987b, 1987c).

It often strikes me, when listening to some of the narratives about people's work experiences within South African public service organisations, that it is usually people with requisite skills and qualifications for their jobs who seem most able to resist corrupting influences, including politicking and various ways of 'beating' the system. They are the ones that are most likely to be rejected by these organisations, celebratory as the latter seem to be of mediocrity. Often enough, one witnesses the very systems that were, purportedly, designed to improve organisational functioning being used to frustrate people until they leave, either by choice or perforce. Administrative and governance processes seem to be increasingly deployed to whip up charges against those who insist on their integrity 
and who dare to challenge evident stupidity. These are the sorts of charges which often start with lengthy suspensions at full pay (legendary as South African public service salaries are, at least at senior levels), and after drawn-out legal processes, end up in undisclosed but undoubtedly expensive settlements. These are, of course, resources diverted away from the public service task.

It is, in contrast, those whose credentials for their positions are suspect, that is, if one disregards political connections, those who seem to have a penchant for subverting due process for political and personal gain, and seem to do so without much hindrance. There appears to be a correlation between a sense of lack in requisite skill on the one hand, and an inclination to collude in anti-task behaviour on the other. Anti-task behaviour can range from hiding behind protocol to pursue all sorts of shenanigans, to outright corruption. Questionable individuals seem also, to be the ones to rise up the public service hierarchies and to do so with impressive agility. Taking their equally incompetent courtiers along for the ride, they all in the long run, help entrench organisational and societal dysfunction.

This is not at all to suggest that all those in senior positions in the public service are ill qualified and/or inherently corrupt and that those who leave or occupy junior positions are necessarily ethical or innocent. Nor is a suggestion being made that governance systems never catch out the 'bad guys'. The point, rather, is to highlight some of the nonsense that goes on within public service entities, often, under the guise of due process.

When one considers that it is not just the target official(s) who are impacted by the relational ruptures, but a whole lot of other people who work and live with them, one begins to appreciate the corrosive nature of dysfunctional organisational practices. Just as people import into their places of work 'stuff' from their personal lives, so do they export into their social spaces, some of the psychosocial fallout from negative work experiences. Decay soon sets in and gets entrenched in people's personal and professional relational spaces. It, in the long run, sets off a whole new set of problems which then join the queue of mounting service demands on state resources. Hence, a sense of merry-goroundedness that one sometimes gets when contemplating public service issues in South Africa.

\section{Problem statement}

As indicated earlier, whilst an impressive body of literature explores the psychodynamics of various forms of social service, the unconscious dynamics of public service work remain largely under-theorised. Herein, I use social defense theory to explore the nature of anxiety and defence in South African public service organisations. Taking seriously the suggestion that socio-cultural institutions are used for both creative and defensive purposes, I explore the following working hypotheses:
- Hypothesis 1: A highly polarised societal landscape in South Africa exacerbates the tensions that typically attend public service work.

- Hypothesis 2: Excessive reliance on positional authority, protocol and governance mechanisms serve as collective defenses against persecutory anxiety emanating from wider society and from an intractable public service task.

- Hypothesis 3: An 'as if' mode of behaviour on the part of policy makers and public officials as well as a fascination with expensive but meaningless rituals lend a defensive character to the culture of public service organisations.

\section{The potential value-add of the study}

The ideas presented in this article have a potential to stimulate critical reflection on the part of various South African stakeholders, and to lead, ultimately, to sustainable social and organisational dynamics. At the societal level, the discussion has a potential to contribute to mature relatedness across the many splits that continue to characterise the South African socio-cultural landscape. As a recent colloquium on social cohesion revealed, poor service delivery and the associated issues of greed and corruption are considered by many South Africans to represent one of the most serious and immediate threats to social cohesion in the country. At the organisational level, an appreciation of the complex and multiple meanings of public service work, as well as the defensive role played by public institutions, have a potential to inspire sustainable change towards an effective public service. Last but not least, it is my hope that the ideas presented will stimulate ongoing empirical research into the unconscious dynamics of public service work.

The discussion is structured as follows: following a brief outline of the article's methodological approach, insights from social defense theory are employed, firstly to make sense of the wider socio-cultural landscape that South African public service organisations find themselves in, and secondly, to make sense of some of the dysfunctionality observed within these institutions. Implications for practice are then highlighted, followed by concluding remarks.

\section{Research design Research approach: Systems psychodynamics}

This article employs systems psychodynamics to make sense of public service work in South Africa. Systems psychodynamics is a broad field of study and practice that combines systems thinking with psychoanalytic concepts to foster deeper understandings of the complex processes that underpin individual and collective behaviour. It represents attempts to extend psychoanalytical insights to wider sociocultural phenomena, including the functioning of groups, organisations and societies at large. In focusing on both the conscious and unconscious dimensions of human behaviour, psychodynamic perspectives make possible, sophisticated understandings of complex organisational and societal phenomena. They, as such, eschew the kind of linear thought processes that tend to yield simplistic and formulaic solutions 
to confounding social phenomena. Service delivery in South Africa is one such phenomenon.

In framing organisations as socio-technical systems, psychodynamic perspectives underscore the fact that people bring to their places of work, both their rational and irrational selves. It is precisely because people's unconscious aims and needs very seldom, if ever, coincide with the requirements of the task at hand, that so much psychodrama and political intrigue characterise places of work. A systemic view of organisations, therefore, makes possible, an appreciation of the wider systemic factors that impact on people's experiences of work life. It is the highly polarised nature of South African society that makes systems psychodynamics a particularly useful frames for making sense of both societal and organisational dynamics in the country.

\section{Research method}

This is a conceptual article. It draws on my experiences as a psychodynamically oriented researcher and as a reflective citizen to make sense of public service dynamics in South Africa. Whilst anecdotal data from various research projects is used to support my claims, the projects did not in themselves seek to examine the psychodynamics of public service work. The studies were national in their scope, and solicited the views of the general members of the public as well as various stakeholder groups on various policy issues and government programmes. They include research into a government community consultation programme, a review of a provincial development strategy, a social cohesion colloquium, and two studies on the impacts and legacies of the 2010 FIFA World Cup. In all of these projects, the diversity of their foci notwithstanding, concerns about public service delivery emerged as a dominant and recurring theme.

It was as I reflected on the various sets of research data, the actual experience of consulting to government departments, as well as my encounters with public service organisations as a citizen, that the ideas presented in this article began to formulate in my mind. It was as I tried to make sense of some of the bizarre phenomena that I experienced and witnessed the possibility that national public service institutions might be under the sway of powerful social defences suggested itself. I struggled and continue to struggle with the incompetency argument: the idea that public officials, a significant number of whom has tertiary qualifications, cannot execute basic administrative functions. They seem astute enough to negotiate their way through the complex and technical detail of governance guidelines, including the Public Finance Management Act (PFMA). Whilst the PFMA and similar governance mechanisms are often used defensively to ensure that officials do things right rather than do the right thing (Dartington, 2004), the point I make is that the characterisation of public officials as incompetent is too easy. It is, in my view, a splitting defence on the part of those fascinated by this explanation.

My personal experiences, as well as research participants' accounts of their own experiences with public service organisations, paint a picture of a bullying and uncaring public service culture and one paralysed by anxiety of a persecutory kind. There is, to be sure, a pervasive siege mentality on the part of public officials (c.f. Dartington, 2004). It manifests in palpable 'us' versus 'them' dynamics that characterise relations across multiple levels of South African society. Splitting and projective processes are evident in relational dynamics across the three spheres of government, across different government departments, and across different socio-cultural groups in the country. They can also be found in relations between government and business formations, between government departments and service providers, and between officials and members of the public.

Whilst this article makes a worthwhile contribution to attempts to theorise public service work, its conceptual nature represents a particular limitation. I remain hopeful, however, that others will, as indicated earlier, draw some inspiration from the discussion and conduct research studies that both problematise and validate some of my observations.

\section{Discussion}

\section{The psychodynamics of public service work in South Africa}

Dartington (2004) and Hoggett (2006) present a compelling case about the inherently complex and contentious nature of public service work. For Hoggett, complexity derives in part from the fact that 'government partly acts as the receptacle for the alienated subjectivity of citizens' (p. 175). This leaves public officials with the unenviable task of having to contain 'unresolved and often partially suppressed value conflicts and moral ambivalence of society' (p. 175). The precarious nature of the life of the public official emanates from the fact that 'those lower in the hierarchy, and the worst paid, have the longest exposure to the clients/patients/students, who project into them their own anxieties about failure' (Dartington, 2004, p. 303). According to Hoggett (2006):

... in the context of welfare societies, the mad, the bad, the sad, the old, the sick, the vulnerable, the failures, and so on, receive not just our compassion but also our fear, contempt and hatred. (Hoggett, 2006, p. 183)

This comes about because in narcissistic cultures, and here I suggest South Africa is one such culture, there is an inherent fear of dependency and concomitantly, poor tolerance for human limits. This sets the scene for a hostile and paranoid relational stance on the part of public officials.

In polarised societies like South Africa, societal ambivalence about public institutions manifests as inter-group tensions. Rather than confront the nature and sources of societal anxiety, racial, ethnic and class attributions become convenient but superficial explanations. It is quite informative, for example, to watch media coverage of service delivery issues across different parts of the country. In some communities, inadequate service delivery is seen through the racialised lens, with community members accusing the 
incumbent African National Congress (ANC) government of only providing services for Black people. Within other communities, particularly where there is a strong opposition party presence, the accusation is often that only the needs of ANC members get attended to. And yet still, amongst those loyal to the ruling party, responsibility for service delivery failure tends to be put squarely on the shoulders of individual officials (not the party or government). Recently in the Western Cape, where the predominantly and/or traditionally White Democratic Alliance (DA) party is the provincial ruling party, accusations of pro-White and prorich bias are rife.

The pervasiveness of these and similar inter-group projections, as indicated earlier, suggests a dominance of paranoid anxiety. As Jaques (1955, p. 479) pointed out, splitting and projection often occur when aspects of the task and/or relationship(s) are experienced as psychically painful or threatening. The defensive response typically involves unconsciously creating artificial us-them subgroups. Unwanted bad internal objects and impulses get projected into the not-me/not-us other(s). The resulting we-they distinctions serve to mask similarities and make it easier to mobilise the different 'other(s)' for scapegoating. This enables the in-group(s) to split off the tension and claim the positive aspects of a polarity, whilst externalising and projecting into the not me-not us 'other(s)', its negative aspects. Interestingly, and underscoring the projective nature of the dynamics at play, both the ANC and the DA were recently caught out in the open toilet saga ${ }^{1}$. The questions that this raises include: what then of earlier claims by the ANC that the open toilets served as evidence of racism and elitism on the part of the DA? What of the claims of competence by the DA and attributions of incompetence to the ANC?

Drawing on Long (2001) I suggest that a deeper understanding of inter-group projections in South Africa, as elsewhere, requires an exploration of the unconscious gain that might reside in splitting and separating our common and complex experience, in both its beauty and its ugliness. There is a need to examine the nature of the underlying pain that the splitting is intended to mask. Taking seriously the suggestion that aspects of public service delivery in South Africa are intractable, a question then arises whether South Africans can bear to acknowledge this impossibility or not. What might such an acknowledgement mean for those sections of South African society that prefer to equate poor service delivery, or incompetence as they prefer to call it, with the post-1994 dispensation, or the Blackness of it? What then of the reality that the White apartheid government was just as incompetent if not more so? On the progressive side of the political spectrum, can this section of society bear to acknowledge that the much celebrated democratic government, and one elected on its struggle credentials, may after all, in some respects, not be that different from the much maligned apartheid government? Now that the monstrous 'other' has been officially 'killed', how willing or

1.This refers to a situation whereby both the DA and the ANC were revealed to have built toilets for people that were open and did not have enclosures. able are these South Africans to confront the monster within and amongst their own? For the 'beneficiaries' and 'victims' of both regimes, can they give up their injured narcissistic pride and delusions of superiority - moral or otherwise - and begin to see the limitations of their polarised and polarising attributions?

\section{Deploying culture as a defence against incompetence}

Jaques (1955) opined that:

... a number of problems which are often laid at the door of human ignorance, stupidity, wrong attitudes, selfishness, or power seeking, may become more understandable if seen as containing unconsciously motivated attempts by human beings to defend themselves in the best way available at the moment against the experience of anxieties whose sources could not be consciously controlled. (Jaques, 1955, p. 479)

Whilst it is hard not to see the behaviour of some public officials and politicians as blatant selfishness, greed and power seeking, the defensive role that this behaviour might be serving is something worthy of consideration. The addiction of some of our leaders to positional power and associated creature comforts, a general tendency to be defensive towards corrective feedback, a pervasive aversion towards excellence, and the bullying culture that all of this seems to engender are a maladaptive response. And so is the continuing acquiescence of those at the receiving end of tyrant behaviour. The dynamics, in the end, threaten the very fabric of South African society: they encourage a dog-eat-dog mindset. One by one, anecdotal evidence suggests, as people witness others 'get away with it', they soon adopt the stance that if you cannot beat them, join them and hope that you are not the one that gets caught and are made example of.

As suggested earlier, the task that awaited the newly elected and inexperienced ANC government in 1994 was a mammoth one. Underscoring precisely this point, a research participant characterised the task of municipal officials as tantamount to carrying sheets of aluminum zinc in windy conditions: 'Kodwa ke noko oomasipala aba sibathwalisa amacangca kuggutha'2 is how he put it. Whilst referring specifically to the enormity and intractability of service delivery at the local level of government, the statement is just as applicable to other spheres. A number of state institutions, including state owned enterprises, national and provincial departments, as well as local municipalities, are simply not coping. My argument here is that the deployment policy of the ruling party, whereby trusted party loyalists are rewarded with lucrative senior positions within state institutions, often without due regard for their suitability for the roles in terms of professional skills and personal qualities, is a defensive response. It is informed by a recognition that people who lack a sound understanding of the task at hand, are more amenable to manipulation and control. A sense of lack also diminishes a person's capacity to give and receive constructive feedback. Hence, a tendency by deployees,

2.The Xhosa phrase loosely translates to: 'Quite honestly though, we are making municipal officials carry sheets of aluminium zinc in a wind storm.' 
once in their positions and confronted with their limitations, to mobilise the public service machinery to defend against feelings of incompetence and the inevitability of failure. In a blatant abuse of their positional or organisational authority, they surround themselves with equally incompetent sycophants and together they bully and marginalise those whose competence can only be experienced as a threat.

Social defense theory helps us see clearly enough the subtle and not so subtle ways in which organisational processes get subverted, not only to cover up corruption, but also to help public service stakeholders defend against anxiety. It helps one understand better some of the bizarre phenomena that often leave one dumbfounded as one witnesses some of the going-ons within some government institutions. There is, in my view, a lot that does not make sense in the South African public service arena. Take the allocation of responsibilities across the three spheres of government, for example. Whilst the progressive language used to talk about inter-organisational arrangements is seductive, for example, notions of 'empowerment' and 'inclusivity', the idea of leaving the most onerous task of service delivery to the least equipped stratum in terms of both financial and human resources, and with full knowledge of the level of need in most local municipalities, makes it hard to take seriously any claims of purposeful intent to meet service delivery expectations. It seems designed, advertently or otherwise, to set up the local sphere for scapegoating. Policy makers surely recognise that a lot of what they promise is pie-in-the-sky stuff and that the public is bound to snap out of its selective state of stupor and start agitating for substance.

The progressive rhetoric seems to be designed to coax people to abandon their critical faculties, and year in and year out, to enthusiastically partake in ritualistic activity. Meaningless rituals include the many activities that always, and after much fan fare and expense, result in very little, if any, impact on the ground. The izimbizo $0^{3}$ programme can be thought of as one such initiative. Whilst framed as community participation and communication forums, they were found by some participants to be just another ANC rally and as an electioneering exercise by the ruling party. Whilst a lot of fan fare and pomp characterised the events, participants indicated that opportunities for meaningful contact and communication with the presidential delegations were limited. Participants reported that there was often very little, if any, follow through action and/or feedback and that the same service delivery issues were raised year after year.

Rituals also include the sort of menial events that people love to embellish with important sounding labels. Just because a meeting takes place in an external and often expensive venue does not make it a strategy workshop. Certainly not if the bulk of the time is, as suggested by another research participant, spent deliberating on mundane day-to-day operational issues. Interestingly, a research participant who imagined his or her role to be principally strategic in nature

3.Izimbizo is a Zulu word for open community meetings within a traditional community setting. was able, during an interview, to come to a realisation that in fact his or her role is quite operational and reactive in nature as he or she spends a significant amount of his or her time responding to urgent and last minute requests from his or her political heads. He or she was also able to acknowledge that most of the strategy workshops that he or she regularly attends are, in reality, extended operational meetings.

\section{Public service delivery in South Africa: A theatre of the absurd}

It is the 'as if' element in the behaviour of politicians, public officials and citizens that lends a defensive character to the functioning of public service organisations. When administrators behave as if they join the public service to do something other than the provide an effective and efficient service to members of the public, when they conduct themselves as if they are politicians rather than administrators, and when attending meetings, workshops, legkotlas ${ }^{4}$ and conferences comes to be mistaken for the actual primary task of public service, one begins to suspect that the public service system may be under the sway of powerful defensive phenomena. It is as if by inducing thoughtlessness (Hirschhorn, 1988; Lazar \& Lohmar, 2000), performativity and busy-ness protect officials from confronting anxiety provoking aspects of their collective experience.

Often enough on television and in the print media, one witnesses various senior politicians visiting 'trouble spots' and communities where the 'poorest of the poor' live. At one level, the public road shows could be read as a signal of a government that is taking people's concerns and grievances seriously enough. After a while, however, if no decisive follow-through action takes place and there are no tangible changes to people's experiences of service delivery, the public display could come to be seen to be but a charade. Form over substance makes a farce of the entire exercise and could come to be experienced as yet another affront on people's sensibilities. The public performances, in my view, serve to deflect attention away from the other spheres of government. The façade of decisiveness and purposefulness paraded in the media, as one senior politician after another, hops over one open sewerage drain to the next, coupled with the fact that one does not get to see local operatives' response, creates an impression that they have nothing to show, and indeed, oftentimes, they simply do not.

One of the structural absurdities that reinforce collective defences within public service organisations is the fact that quite often, senior government officials have reporting to them, people who are senior to them within political party structures. This inevitably raises authorisation issues. A research participant told a story of two female premiers who held fairly junior if not insignificant positions with the ruling party and had party heavyweights reporting to them. So untenable was their situation that one would, every time before attending provincial executive committee (PEC)

4.Lekgotla is a Sesotho term for meetings within a traditional community setting. It is currently used by South African government organisations to refer to strategy planning meetings. 
meetings, invite trusted staff to join her in prayer. This was to prepare herself for the abuse and humiliation that she knew some of her reports would subject her to. The second premier coped with the situation by letting her report do as he pleased in the hope that this would spare her embarrassment during party structure meetings.

\section{Implications for practice}

A psychodynamic perspective on public service work stands to inform meaningful interventions beyond such formulaic and predictable solutions as capacity building and strengthening of governance mechanisms. There is, as we all know, nothing new about these and similar technical and managerialist interventions. They have been touted, albeit by some other names, since the advent of modern organisation. What is puzzling, or maybe not, is the fact that despite a general awareness of the underlying factors to poor public service delivery in South Africa, as well as possible solutions (Atkinson, 2007; Koelble \& LiPuma, 2010; Makgetla, 2007) this knowledge is failing to translate into an effective public service. Whilst the usual suspects, including corruption and lack of technical skills are contributing factors, and are cited ad nauseam in the national discourse, they are, in my view, only a part of the problem. It is precisely for that reason that having in place some of the most advanced policy frameworks and governance mechanisms in the world has thus far failed to adequately deal with maladministration in the national public service. It remains doubtful, also, whether throwing in gaol the few that are caught (and happen not to be political heavyweights), will get rid of the problem. It is likely, instead, to add even more pressure to what is an already over-extended public purse as more prisons would then need to be built - and resourced.

There is an onus on those who work for social and organisational change to try to surface inherent task anxiety and to help ensure that defensive phenomena do not completely dominate public service institutions. There is a need to examine closely the kinds of forces that may be making public service officials feel under siege and their position(s) precarious. There is a need to explore earnestly the kinds of complex and turbulent social dynamics that might be making workers feel unable to cope with their job demands. These factors include resource constraints as well as other less acknowledged or un-acknowledgeable forces, including some of the unexpected psychosocial fallouts from the transformational project.

The likelihood that some workers may have simply given up on the public service project and may have stopped caring is a possibility that cannot be overlooked. Also, when one considers the unacceptably high unemployment rate in South Africa and the reality that for many, public service might not be their first career choice, one begins to appreciate that there might be a lot of public servants who actually hate their jobs. Feeling trapped and stuck without a way out, task corruption (Chapman, 2003) under such circumstances cannot be ruled out.

In evoking Jaques' counsel earlier, in an attempt to understand differently some of contemporary dysfunctionality, the intention was to remind people to spare a thought for those public officials who may not necessarily be corrupt but who may find themselves colluding by choosing silence or turning a blind eye as others continue to pervert organisational processes for personal and political gain, and at the expense of the common good. This is the group that, in my view, tends to be overlooked in public and intellectual discourse. And yet it could very well be the cohort that may hold the key to turning the public service around. In a concurrent process, therefore, even as people seek to root out corruption and deal with nonperformance, care ought to be taken not to direct all efforts and resources to 'problem' officials only. Indeed, a school principal bemoaned the fact that his school's excellence, whilst celebrated by policy makers, seemed to be resulting in it being marginalised or overlooked during interventions to improve educational outcomes. He suggested that the school was in fact being punished for being good.

Some form of psychosocial support for public officials could also help contain some of the anxiety that attends public service work. This would not only help those in leadership to assume their roles in mature and effective ways, but would also capacitate followers with requisite relational skills for responsible followership. Support for public officials, particularly those working within socioeconomically depressed communities, would also help alleviate some of the emotional burden that work in the domain inevitably entails.

\section{Conclusion}

In the preceding discussion I sought to illustrate how aspects of the South African public service are being deployed for collective defensive purposes. My aim was to alert those working in the domain to be mindful always of the many ways in which essential organisational processes are possibly being misused to hinder effective public service work. I drew on psychodynamic perspectives to explore the public service delivery conundrum and attempted to show how manifest dysfunctional dynamics might derive primarily from societal and task-related anxiety. The article underscores the need for those who work for public service change to closely examine, for each public service institution, the intrinsic nature of its primary task(s), the potential psychic meaning(s) of the work, and the anxieties that attend to these meanings. This exercise will inevitably surface a fair amount of tension for leaders and followers alike, as well as for members of society. In facilitating purposeful change, it is important that this tension is worked with rather than defended against. As Menzies-Lyth (1988) warned, it is only when people fail to identify and work through individual and collective defences that effective task performance is hindered and individual and collective growth jeopardised. 


\section{Acknowledgements Competing interests}

The author declares that she has no financial or personal relationship(s), which may have inappropriately influenced her in writing this article.

\section{References}

Atkinson, D. (2007). Taking to the streets: Has developmental local government failed South Africa? In S. Buhlungu, J. Daniel, R. Southall \& J. Luchtman (Eds.), State of the nation: South Africa 2007 (pp. 53-77). Cape Town: HSRC Press.

Bain A (1998). Social defences against organisational learning. Human Relations, 51(3), 413-429. http://dx.doi.org/10.1023/A:1016952722628

Bollas, C. (1987). The shadow of the object: Psychoanalysis of the unthought known London: Free Association Books.

Bott-Spillus, E. (1990). Asylum and society. In E. Trist \& H. Murray (Eds.), The socia engagement of social science: The socio-psychological perspective (pp. 586-614). London: Free Association Books.

Chapman, J. (2003). Hatred and corruption of task. Journal of Organisational and Social Dynamics, 3(1), 40-60.

Cilliers, F., \& May, M. (2010). The popularisation of Positive Psychology as a defence against behavioural complexity in research and organisations. South African Journal of Industrial Psychology/SA Tydskrif vir Bedryfsielkunde, 36(2), 917-927.

Cohn, N. (1994). Attending to emotional issues in a special care baby unit. In A. Obholzer \& V.Z. Roberts (Eds.), The unconscious at work: Individual and organisational stress in human services (pp. 60-66). London: Routledge.

Cummins, A. (2002). The road to hell is paved with good intentions: Quality assurance as a social defense against anxiety. Organisation \& Social Dynamics, 2(1), 99-119.

Dartington, T. (2004). In defence of inefficiency. Organisational \& Social Dynamics, $4(2), 298-310$.

Dempsey, K. (2007). Public Sector Value Statements as Talismans against Evil. Pape Presented at The International Society for the Psychoanalytic Study Organization Symposium, 22 June - 01 July, Stockholm, Sweden. Retrieved November 09, 2011, from http://www.katedempsey.com.au/publications/Value_statements as_talismans_against_evil.pdf

Flinders, S.L. (2003). The Internal Struggles of Aging. Journal of Psychoanalysis, Culture \& Society, 8(2), 258-262. http://dx.doi.org/10.1353/psy.2003.0033

Gibson, K., \& Swartz, L. (2001). Psychology, social transition and organizational life in South Africa: 'I can't change the past - but I can try'. Psychoanalytic Studies, 3(4), 381-392. http://dx.doi.org/10.1080/14608950120103668

Gibson, K., \& Swartz, L. (2000). Politics and emotion: Working with disadvantaged children in South Africa. Psychodynamic Counselling, 6(2), 133-153. http://dx.doi. org $/ 10.1080 / 135333300407512$

Gould, L.J., Ebers, R., \& Clinchy, M.M. (1999). The systems psychodynamics of a joint venture: Anxiety, social defences and the management of mutual dependence. Human Relations, 52(6), 697-722. http://dx.doi. org/10.1177/001872679905200602

Hirschhorn, L. (1988). The workplace within: Psychodynamics of organizational life Cambridge: The MIT Press.

Hoggett, P. (2006). Conflict, ambivalence and the contested purpose of public organizations. Human Relations, 59(2), 175-194. http://dx.doi. org/10.1177/0018726706062731
Jaques, E. (1955). Social systems as a defence against persecutory and depressive anxiety: A contribution to the psycho-analytical study of social processes. In M Klein, P. Heimann \& R.E. Money-Kyrle (Eds.), New directions in psycho-analysis: Klein, P. Heimann \& R.E. Money-Kyrle (Eds.), New directions in psycho-analysis:
The significance of infant conflict in the pattern of adult behaviour (pp. 478-498). The significance of infant conflict

Klein, M. (1959). Our adult world and its roots in infancy. Human Relations, 2, $291-$ 303. http://dx.doi.org/10.1177/001872675901200401

Koelble, T.A., \& LiPuma, E. (2010). Institutional obstacles to service delivery in South Africa. Social Dynamics, 36(3), 565-589. http://dx.doi.org/10.1080/02533952.2 010.518002

Lazar, R.A., \& Lohmar, M. (2000). A search for new partners or an invitation to join a harem? The interplay of emotion and structure in the expansion process of a consulting firm. Paper Presented at The International Society for the Psychoanalytic Study Organizations Symposium, 22-24 June, London, England. Retrieved November 09, 2011, from http://www.ispso.org/Symposia/archives. htm

Long, S.D. (2001). Conflict and co-operation: Two sides of the same coin. In R. Wiesner \& B. Millet (Eds.), Management and organisational behaviour: Contemporary challenges and future directions (pp. 184-197). Brisbane: Wiley.

Makgetla, N.S. (2007). Local government budgets and development: A tale of two towns. In S. Buhlungu, J. Daniel, R. Southall \& J. Luchtman (Eds.), State of the nation: South Africa 2007 (pp. 146-170). Cape Town: HSRC Press.

Mawson, C. (1994). Containing anxiety in work with damaged children. In A. Obholzer \& V.Z. Roberts (Eds.), The unconscious at work: Individual and organisational stress in human services (pp. 67-74). London: Routledge.

Menzies-Lyth, I. (1988). A psychoanalytic perspective on social institutions. In E.B. Spillius (Ed.), Melanie Klein Today: Vol. 2, Mainly Practice (pp. 284-299). London: Tavistock Publications.

Mnguni, P.P. (2010). Anxiety and defense in sustainability. Psychoanalysis, Culture \& Society, 15(10), 117-135. http://dx.doi.org/10.1057/pcs.2009.33

Mnguni, P.P. (2008). Mutuality, reciprocity and mature relatedness: A psychodynamic perspective on sustainability. Unpublished PhD thesis, Swinburne University of Technology, Melbourne, Australia.

Obholzer, A. (1994). Managing social anxieties in public sector organizations. In A. Obholzer \& V.Z. Roberts (Eds.), The unconscious at work: Individual and organisational stress in human services (pp. 169-178). London: Routledge. http:// dx.doi.org/10.4324/9780203359860

Obholzer, A., \& Roberts, Z.V. (Eds.). (1994). The Unconscious at work: Individual and organisational stress in human services. London: Routledge.

Roberts, Z.V. (1994a). Till death do us part: Caring and uncaring in work with the elderly. In A. Obholzer \& V.Z. Roberts (Eds.), The unconscious at work: Individual and organisational stress in human services (pp. 75-83). London: Routledge.

Roberts, Z.V. (1994b). The self-assigned impossible task. In A. Obholzer \& V.Z. Roberts (Eds.), The unconscious at work: Individual and organisational stress in human services (pp. 110-118). London: Routledge.

Smith, K.K., \& Berg, D.N. (1987a). A paradoxical conception of group dynamics. Human Relations, 40(10), 633-658. http://dx.doi.org/10.1177/001872678704001001

Smith, K.K., \& Berg, D.N. (1987b). The management of paradox in the educational process. Organizational Behaviour Teaching Review, 12(1), 1-15.

Smith, K.K., \& Berg, D.N. (1987c). Paradoxes of group life: Understanding conflict, paralysis and movement in group dynamics. San Francisco: Jossey-Bass.

Speck, P. (1994). Working with dying people: On being good enough. In A. Obholzer \& V.Z. Roberts (Eds.), The unconscious at work: Individual and organisational stress in human services (pp. 94-100). London: Routledge.

Willshire, L. (1999). Psychiatric services: Organizing impossibility. Human Relations, 52(6), 775-804. http://dx.doi.org/10.1023/A:1016994532507 